\title{
Sobre os ciborgues como figuras de
}

borda

\author{
Dolores Cristina Galindo \\ Núcleo de Estudos e Pesquisas em Práticas Discursivas e Produção de Sentidos \\ Pontifícia Universidade Católica de São Paulo
}

doloresgalindo@ig.com.br

\section{Resumen}

Nessa apresentação, propomos uma reflexão sobre a agência de objetos compreendidos como partícipes e produtos de redes heterogêneas. O que chamamos de objetos não apresenta uma ontologia diferente do que chamamos de pessoas - ambos resultam de processos de estabilização que atribuem intencionalidade aos humanos e instrumentalidade às coisas (Latour, 1994). Note-se que compreender a ação das coisas ou objetos não implica em propor uma espécie de animismo que atribua intencionalidade às coisas (Tirado, 2000), nem a negação de intencionalidade às pessoas. A ação é propriedade de um coletivo no qual alguns entes adquirem propriedades estáveis em determinadas circunstâncias nas quais agem. Incorporar a ação de entes aos quais não é conferida humanidade - os objetos - constitui desafio que, ao lado de outros autores, nos propomos a enfrentar a partir da análise de situações ocorridas em diferentes contextos: artístico (Gullar, 1966; Oiticcica, 1968), científico (Mol, A., 2000) e ecológico (Tirado et al, 2003).

Palabras clave: construcionismo; práticas discursivas; materialidades; agências; objetos

"Neo: Porque meus olhos doem?

Morfeus: porque você nunca os usou

Extrato de diálogo retirado do filme Matrix na versão legendada para português

No contexto dos estudos da ciência, a figura dos ciborgues tal como proposta por Donna Haraway no texto Manifiesto para Cyborgs ${ }^{1}$ é freqüentemente mencionada como possibilidade de superação das dicotomias homem-máquina; organismo-máquina e para questionar a naturalidade das categorias gênero e sexo. Em meu próprio percurso, a leitura desse texto foi fundamental pelo caminho não dicotômico de reflexão adotado pela autora. $\mathrm{Na}$ apresentação de hoje, me concentrarei na reflexão acerca da figura dos ciborgues no contexto contemporâneo marcado pelo surgimento de um genosticismo tecnológico e, em seguida, deslocarei a mesma metáfora para o contexto da sociabilidade com objetos, fazendo diálogo, sobretudo, com a contribuição de Francisco Tirado.

O texto resulta de uma reflexão breve sobre um certo modo de constituição de tecido social contemporâneo que questiona as fronteiras entre o discurso, o técnico, o maquínico, o social; onde se

\footnotetext{
${ }^{1}$ Usarei como base para argumentação a tradução feita para o espanhol intitulada Manifiesto para Cyborgs: ciência, tecnologia e feminismo socialista no final do século XX publicado no livro Ciência, cyborgs y mujeres: la reinvención de la naturaleza.
} 
proliferam as criaturas híbridas (vírus, mulheres com próteses de silicone; tecnologias úmidas etc.); onde o tecido social é adensado de forma a comportar elementos de diversas ordens e tempos. Latour, no livro Jamais Formos Modernos ${ }^{2}$, anunciava a proliferação de seres nos quais não é possível distinguir entre o natural e o social; o humano e maquínico. Estariam sendo gerados há muito tempo, porém sem que fosse feito debate público acerca de sua proliferação. Tais seres variavam desde o vírus HIV ao buraco de ozônio na atmosfera, no conjunto desses híbridos podemos incluir o surgimento dos ciborgues ${ }^{3}$.

É possível argumentar que os híbridos estiveram aí desde sempre, que sempre estivemos relacionando-nos constitutivamente com objetos/coisas e, em certo sentido, deles dependentes. No século $\mathrm{XV}$, as pessoas alteram seus ritmos de vida com a introdução mais consistente dos aparelhos mecânicos ${ }^{4}$, a exemplo da cadência dos relógios. ${ }^{5}$. Desde o século XIX com a convivência de máquinas mecânicas, a vapor e em seguida elétricas, a vida passou a ser organizada com mais velocidade. Pode-se fazer mais, pode-se voltar às classificações das eras pré-históricas e argumentar que a periodização mais usual faz referência ao tipo de instrumentos usados pelo homem préhistórico; as famosas idades das pedras (lascada, polida) e depois do bronze.

Acho que fazer esse retroceder histórico se incorre numa certa armadilha. É necessário conferir uma certa singularidade às contemporâneas configurações de agenciamento entre pessoas e máquinas que marcam as últimas décadas nas quais se vive a co-existência dos modelos mecânico, energético, informacional e cibernético ${ }^{6}$ e seus diversos maquinários/fluxos de informação/fluxos de controle ${ }^{7}$. Creio não ser útil analiticamente dar ao homem pré-histórico, ao acrobata no século XVII e sua rede de segurança ou a mulher sertaneja e sua enxada à classificação de um ciborgue. A configuração ciborgue só se torna possível, em sua plenitude, no contexto dos avanços tecnológicos e da cibernética e, ainda assim, em alguns espaços-tempo da contemporaneidade por meio da intensificação introduzida pelas novas tecnologias de informação.

Ciborgues são criaturas do final do século $X X$; são monstros surgidos a partir da introdução de recentes tecnologias que apontam para os limites da comunidade nas imaginações ocidentais, como os centauros e amazonas na Grécia antiga ou os gêmeos e hermafroditas na França moderna. São apresentados por Haraway como o sonho utópico da esperança de um mundo monstruoso sem gêneros, podendo funcionar como possível saída do labirinto dos dualismos pelos quais temos explicado nossos corpos, ferramentas e a nós mesmas ${ }^{8}$.

No manifesto de Haraway, o ciborgue procura ocupar uma figura de borda, ou seja, uma figura anômala, por meio da qual se pode acessar a uma matilha; uma figura de passagem e de crítica. Por

${ }^{2}$ Latour, B (2000) Jamais Fomos Modernos. São Paulo: ed. 34.

3 Há uma diferença nas argumentações de Latour e Haraway no sentido de que nesse livro, o primeiro ao reforçar a ação de não-humanos ainda trabalha com uma dicotomia que a figura do ciborgue procura desfazer.

${ }^{4}$ Foram inseridos moinhos, canhões, relógios e autômatos que pareciam vivos.

${ }^{5}$ Sibilia, P. (2002) O Homem pós-orgânico: corpo, subjetividade e tecnologias digitais. Rio de Janeiro: ed. Relume-Dumará.

${ }^{6}$ Santaella, L. (2003) Culturas e Artes do Pós-Humano: da cultura das mídias à cibernética. São Paulo: ed. Paulus.

${ }^{7}$ Teria havido aí uma transição de uma engenharia de forças para uma engenharia de comunicação, ou seja, e uma economia de energia a uma economia baseada na reprodução acurada de sinais (Santaella, 2002).

${ }^{8}$ Haraway, pp. 311. 
anômalo entende-se não o a-normal ${ }^{9}$ que qualifica algo que contradiz uma regra, mas designa o desigual, o rugoso, a aspereza, a ponta da desterritorialização, definindo-se não em função de características que lhe são próprias, mas como uma posição ou um conjunto de posições em relação a uma multiplicidade ${ }^{10}$. Mas se, por exemplo, o capitão Ahab desejava matar Moby Dick, não é o acontece com o Ciborgue que não é uma grande muralha branca a ser atravessada.

$\mathrm{O}$ anômalo avizinha-se da figura do monstro ${ }^{11}$ enquanto dispositivo que confere inteligibilidade a processos sociais. Como o anômalo, o monstro aparece como um fenômeno ao mesmo tempo extremo e extremamente raro. Ele é o limite e o ponto de inflexão da lei (...). O monstro combina o impossível com o proibido ${ }^{12}$, sem que deflagre da parte da lei uma resposta legal. A passagem para a proposição legal acompanha a passagem do monstruoso para o anormal, se o monstro é uma exceção, o indivíduo a ser corrigido é um fenômeno corrente inscrito em uma mecânica de criação de corpos dóceis. Retomando Pierre Levy, podemos afirmar que as figuras monstruosas e anormais inscrevem a reflexão no campo do virtual que não se opõe ao real, mas abre linhas de fuga em relação ao presente e agem no presente enquanto potência.

Até aqui falamos de ciborgues, mas não demos qualquer definição. O que são ciborgues? A que tipo de agenciamento entre coisas e pessoas faz referência? Bem, a nomeação ciborgue foi cunhada em $1960^{13}$ para aludir a homens-máquina dotados de auto-regulação em estudos acerca de problemas que viagens espaciais ocasionavam à neurofisiologia de humanos. Daí em diante, o termo migrou para a fiç̧ão científica e se misturou a outros tipos de configurações nos quais o mais importante não era o elemento maquínico, mas o informacional ${ }^{14}$. O corpo de carne foi cedendo espaço ao corpo maquínico e, em seguida, ao corpo informacional. $E$ as máquinas também mudaram, de agentes vistos como extensões ou maximizações da força mecânica do corpo, passaram a produzir informação, a serem dotadas de sistemas úmidos de sensações, a serem dotadas de inteligência ${ }^{15}$.

Do ciborgues da literatura, do cinema e da engenharia espacial, não é possível esquecer, a exemplo da epígrafe deu origem a esse texto retirada do filme Matrix. Mas nesse trabalho falarei, sobretudo, da releitura da figura do ciborgue feita por Donna Haraway ${ }^{16}$ que elevou a expressão ao estatuto de uma categoria conceitual e política. Com a expressão "ciborgue" queria abrir para a heterogeneidade, para a ambigüidade e para a desnaturalização dos corpos e suas categorias de classificação, por isso os ciborgues não vêm do barro e não voltam ao pó. Como enuncia Donna Haraway o ciborgue se situa decididamente do lado da parcialidade, da intimidade, da perversidade. É opositivo, utópico e de nenhum modo inocente. (...) Os ciborgues não são reverentes, não recordam do cosmo, desconfiam do holismo, mas necessitam conectar $(. . .)^{17}$.

\footnotetext{
${ }^{9}$ A diferenciação entre anômalo e anormal usada por Deleuze e Guatarri constituem uma retomada de uma diferenciação feita por Caguilhem em O Normal e o Patológico.

${ }^{10}$ Deleuze e Guatarri. Lembranças de um feiticeiro II. In: Mil Platôs, vol. 4. pp. 26.

${ }^{11}$ Foucault, M. (2002) Os Anormais. São Paulo: Martins Fontes.

${ }^{12}$ Foucault, M (2002), pp. 71

${ }^{13}$ O termo foi cunhado inicialmente por Clynes e Nathan em 1960. Os ciborgues foram propostos como solução para os problemas advindos do uso de humanos para realização das viagens espaciais.

${ }^{14} \mathrm{O}$ corpo fluido e cambiante de alguns personagens de Matrix, a exemplo, dos agentes.

${ }^{15}$ Num horizonte de ficção lembre-se aqui do filme "Inteligência artificial", onde a criatura buscava desesperadamente numa nova yorque inundada o amor que atribuía a uma mãe.

16 Manifesto para Ciborgues.

${ }^{17}$ Haraway, Donna , pp. 256.
} 
Haraway fala como uma feminista e com essa nova categoria conceitual-política queria deslocar a discussão de uma lógica de contradição entre humanos e máquinas; entre o orgânico e o inorgânico; entre o físico e o não físico. A política dos ciborgues é a luta (...) contra o código único que traduz à perfeição todos os significados, o dogma central do falocentrismo. Se deve a isso que a política dos ciborgues insista no ruído e seja partidária das fusões ilegítimas entre animal e máquina. São estes acoplamentos que fazem do homem e da mulher tão problemáticos, subvertendo a estrutura do desejo, a força imaginária para gerar linguagem e o gênero, alterando a estrutura e os modos de reprodução da identidade ocidental ${ }^{18}$. Era essa a potência de simbiose que fascinou a Haraway, como escreve Francisco Tirado:

Os ciborgues fascinaram a Haraway porque ajudam a diluir clássicas tensões entre máquinas e organismos, entre o natural e o artificial, entre a mente o corpo, o feminino e o masculino, o eu e o outro, o sujeito e o objeto. $E$ ajuda a diluir tais dicotomias gerando uma figura ou um conceito que as incorpora em uma mesma e única entidade ou estrutura. Quer dizer, com o ciborgue, nosso campo de análise ao invés de ser o sujeito e suas relações, o objeto e suas relações ou o espaço que há entre eles para se converter em uma entidade ou plano distinto que incorpora de maneira imanente a essas figuras e suas relações ${ }^{19}$.

Ciborgues falam da simbiose entre orgânico e inorgânico por meio do uso de tecnologias que se misturam ao corpo. Outra vez mencionando Francisco Tirado (2000), na figura dos ciborgues, sujeito e objeto se anulam como noções ontológicas para constituir meros momentos de uma imagem de nível diferente que as absorve. Os ciborgues têm como característica a heterogeneidade constitutiva onde as entidades que o compõe só ganham sentido interativamente, sendo os objetos e as pessoas efeitos provisórios ${ }^{20}$. Ao discutir a miniaturização das novas tecnologias, apresenta os ciborgues como éter, quinta-essência; são apresentadas como criaturas monstruosas e ilegítimas.

O ciborgue é ao mesmo tempo ficção e realidade, portanto, não pode ser compreendido apenas no plano da historicidade, é necessário remete-lo às linhas de fuga que o ligam ao campo do possível. Ciborgues são um certo modelo de agenciamento que envolve pessoas e coisas que assumem configurações ontológicas singulares rompendo velhos dualismos. São configurações ontológicas mais próximas do rizoma que comporta o crescimento das dimensões numa multiplicidade que muda necessariamente de natureza à medida que ela aumenta suas conexões. Ciborgues falam da reconfiguração de fronteiras corporais e de encaixes políticos entre elementos de diversas ordens.

Um ciborgue é ao mesmo tempo máquina, corpo e metáfora, todos pensados e imersos na prática em termos de comunicações. Num modelo devedor da cibernética ${ }^{21}$, os objetos e as pessoas se fundem,

\footnotetext{
${ }^{18}$ Haraway. Pp. 302.

${ }^{19}$ Francisco Tirado. Capitulo 3. tesis de doctorado.

${ }^{20}$ El cyborg nos recuerda que las conexiones entre nosotros y con las cosas que nos rodean se dan por todas partes, de cualquier manera y en cualquier momento; y que tal conexión ineluctablemente nos transforma, y vuelve a retransformar, en un proceso agónico sin principio ni final. Somos traducidos sin descanso, traducimos incesantemente. $Y$ el devenir de esas marañas de conexiones y entidades heterogéneas en las que somos traducidos tiende de manera casi inevitable hacia un resultado o efecto -un estado acabado o un objeto-, pero que es al mismo tiempo un resultado incierto y provisional. (Tirado, 2000)

21 "Nuestros tejidos cambian en tanto que vivimos: la comida que tomamos y el aire que respiramos se transforman en carne de nuestra carne y hueso de nuestro hueso, y los elementos momentáneos de nuestra carne y hueso salen de nuestro cuerpo cada día cuando excretamos. No somos sino
} 
não sendo nenhum deles pontos de partida ou de chegada, esse é o horizonte de Haraway acerca da sociabilidade com objetos, como o afirma Francisco Tirado, um dos psicólogos sociais que tem estudado como brilhantismo a sociabilidade com objetos. Ciborgue enquanto metáfora que borra as fronteiras entre humanos e não humanos tem encantado a vários pensadores, inclusive, a Tirado que a classifica como um verdadeiro laboratório metafísico para romper dicotomias:

A metáfora do ciborgue se apresenta, assim, como algo mais que uma inovação possível, graças aos novos entornos eletrônicos ou aos novos desenhos de interfaces. Trata-se de todo um laboratório metafísico que permite examinar o sentido do que entendemos por real, imaginário, possível ou impossível. Estamos ante um experimento cujos efeitos ameaçam transformar o que entendemos por conhecimento e o que assumimos como sendo ciência.

A biotecnologia tem se constituído um dos campos de proliferação da figura do ciborgue. No imaginário biotecnológico contemporâneo, a natureza deixou de ser entendida por um regime mecânico-geométrico e passou a ser entendida por um modelo informático-molecular ${ }^{22}$. Também mudaram as formas de poder que passaram do predomínio das disciplinas para o predomínio do controle disperso, por vezes, miniaturizado e materializado em tecnologias que podem acompanhar as pessoas a céu aberto. Por exemplo, desde 2001, a Motorola e Affymetrix, vêm fabricando chips de DNA que juntam em uma mesma peça vidro, silício e fragmentos de material genético humano. Tais dispositivos são utilizados para diagnosticar doenças como câncer e diabete ${ }^{23}$ e outros dispositivos vem sendo produzidos: coleiras eletrônicas, computadores para vestir. Novos dispositivos para curar, proteger ou produzir imagens artísticas ou artístico-cientificas ${ }^{24}$; novos dispositivos de biopolítica.

Os ciborgues integram a passagem de uma sociedade disciplinar a uma sociedade de controle ${ }^{25}$ que penetra nos corpos, rompendo a pele como fronteira de separação e valorizando os fluxos em detrimento do sólido; o sub-atômico em detrimento do geométrico; um poder em redes de fluxos e não mais apenas por confinamento dos corpos indóceis. Inscrevem-se num contexto marcado pelo avanço da biotecnologia, da eletrônica e da microeletrônica, vivem em um mundo intimamente reestruturado por meio de relações sociais da ciência e tecnologia ${ }^{26}$ que estariam gerando novas formas sociais que por sua vez demandam novas formas de compreensão.

O ciborgues se inserem num contexto marcado pela passagem da ação de instituições à ação de extintuições que constituem um dispositivo de análise cunhado por Domenèch e Tirado. ${ }^{27}$ As instituições se caracterizam por uma materialidade dura; definem-se em um plano; apresentam relações espessas e operam por semelhança e limitações, a exemplo das escolas. As extintuições, por sua vez, apresentam mescla de materialidades; assentam-se em planos que flutuam; apresentam relações flutuantes e variáveis; sociabilidade flutuante e operam por divergência e criação e, ao

remolinos en un río de aguas que no dejan de fluir. No somos cosas que permanecen, sino modelos que se autoperpetúan." Wiener (1954:86 apud Tirado, 2000).

${ }^{22}$ Sibilla, $P$.

${ }^{23}$ Sibilla, $P$.

${ }^{24}$ Penso aqui nos recentes trabalhos de cooperação entre artistas e cientistas, e exemplo daqueles

realizados no MIT, donde destaco Sterlac que vem sendo muito citado entre nós.

${ }^{25}$ Deleuze e Guatarri

${ }^{26}$ Hraway, pp. 282.

${ }^{27}$ Domenech y Tirado (2002) Lo Virtual e lo Social. Athenea Digital. 
fechamento das instituições opõe a captura, à exemplo das universidades abertas que operam por internet. Não se trata de uma desistintucionalização progressiva, mas numa mudança na natureza das instituições.

Como assinala Haraway, não existem corpos objetos, espaços ou corpos sagrados por si mesmos, qualquer componente pode ser conectado com qualquer outro sem pauta e o código correto pode ser construído para o processamento de sinais em uma linguagem comum ${ }^{28}$. Haraway vê as tecnologias de comunicação e biotecnológicas como ferramentas para reconstruir o corpo das mulheres, onde os discursos científicos e as tecnologias seriam como momentos congelados de interações sociais fluidas que as constituem em relação às quais produzem significados. A produção de uma linguagem de códigos seria um espaço para desmontar antigas heterogeneidades, antigas dicotomias, ao invés de propor um retorno ao corpo, como o fizeram as feministas na década de setenta, propõe trabalhar na confusão das fronteiras, no estabelecimento de novas combinações. O estabelecimento de redes, característico as novas estratégias das multinacionais biotecnológicas se veria convertido numa estratégia política feminista ${ }^{29}$, nas novas fusões com animais e máquinas, as mulheres talvez pudessem aprender como não ser um homem - encarnação do logos ocidental ${ }^{30}$.

Usar a metáfora ciborgue implica considerar a tecnociência ou a medicina aliada às novas biotecnologias. Que mudanças às tecnologias têm trazido? Como aponta Paula Sibilia, o discurso característico da tecnociência se dirige às energias ou às informações e não à matéria, uma vez que a própria matéria passa a ser entendida como energia, o que em física, tem sido feito, sobretudo, em pesquisas se concentram num nível quântico. Da massa e energia à informação; do sólido ao fluido.

Em alguns contextos, o discurso da tecnociência tem sido incorporado a movimentos neognósticos, vindo a reforçar as antigas dicotomias entre organismo-máquina e mente-corpo. Como afirma Le Breton $^{31}$, o corpo é visto por alguns entusiastas das novas tecnologias como um vestígio indigno fadado a desaparecer em breve. (...) Esses novos gnósticos dissociam o sujeito de sua carne perecível e querem imaterializa-lo em benefício do espírito, único componente digno de interesse ${ }^{32}$. Ao corpo cibernético opõe-se o corpo de carne; refaz-se a dicotomia entre orgânico e maquínico, dando a esse último o privilégio que logo é perdido para o privilégio da mente/informação.

$\mathrm{Na}$ ficção científica, para ilustrar o que estamos falando acerca de neognosticismo e da reafirmação da dicotomia mente-corpo, vale lembrar uma das cenas do filme Matrix. Neo, um dos principais personagens, passou por uma transformação física na qual foram recompostos seus músculos e acoplado sistema de informação. No espaço da Matriz ocorre uma luta, Neo que, simultaneamente está deitado na nave, depois do embate, coloca os dedos na boca e vê que estes ficaram sujos de sangue. Ocorre o seguinte diálogo: Neo: Achei que [a luta] não era real?/ Morfeus: Sua mente torna real./Neo: Se você é morto na Matrix, você morre aqui?/Morfeus: o corpo não vive sem a mente. Observe-se que aqui o neognosticismo aparece na figura de um personagem dissidente no filme Matrix, porém aparece também, sob um outro ângulo, na fala dos personagens responsáveis pelo controle da cidade. Um dos agentes diz: os seres humanos são uma doença e nós somos a cura. Há

\footnotetext{
${ }^{28}$ Haraway, op. cit., pp. 278.

${ }^{29}$ Haraway, op. cit., pp 291.

${ }^{30}$ Haraway, op. cit., pp. 297.

${ }^{31}$ Le Breton (2003) Adeus ao corpo. In: O Homem-máquina: a ciência manipula o corpo. São Paulo: ed. Companhia das Letras.

${ }^{32}$ Le Breton (op. cit.), pp.123.
} 
em todo filme Matrix uma exaltação da mente ou da informação que vem acompanhada do questionamento radical da realidade e do tipo de poder característico de uma sociedade de controle.

No campo das seitas religiosas, vale recordar a comunidade dos extropianos que tem trabalhado no sentido de desenvolver aparatos técnicos capazes de armazenar informações a fim que de que possam viver eternamente e, em momento, posterior voltar aos seus corpos que se encontrariam congelados $^{33}$. Mesmo os desenhos infantis incorporaram os ciborgues como heróis, a exemplo do recém-lançado mangá Cyborg 009 no qual duelam bons e maus ${ }^{34}$. Sobre jogo de RPG intitulado Ciberpunk 2020, escreve-se em um artigo de divulgação O livro adverte, em um dos seus capítulos: esqueça tudo o que você sabe sobre Ciborgues. Tudo! Anos 2000. Ser ciborgue é uma coisa fina. Implantes cibernéticos são projetados para um estilo de vida altamente móvel e dinâmico. Você pode ser equipado com chips de dados implantados em seu sistema nervoso, para aumentar sua performance no jogo de tênis, ou miniarmas bioengendradas para proteção pessoal. O ciborgue dos anos 2000 é o que existe de mais avançado em termos de biotecnologia ${ }^{35}$."

Os últimos anos também têm sido marcados por acirrados debates acerca da bioética envolvida nos novos seres híbridos, a exemplo do campo da reprodução assistida. Gradativamente o que era da ordem do monstruoso passa a ser incorporado ao processo de normalização; do monstro ao anormal. Obviamente, nesse contexto, as discussões não fazem alusão necessária à expressão "ciborgue", sendo utilizada apenas por alguns pesquisadores como princípio de inteligibilidade. A passagem do monstruoso ao anormal ainda está em curso e participamos dos primeiros capítulos, ainda veremos os intensos debates acerca das nanotecnologias.

Certamente, os ciborgues que envolvem biotecnologia dos quais fala Haraway foram retirados da ficção científica feminista, mas o uso da metáfora tem sido expandido a outros contextos por diversos trabalhos de pesquisa posteriores e vem se proliferando paralelamente em filmes, jogos infantis etc. Surgem novos cenários nos quais os cborgues se proliferam na interface entre biotecnologia e realidade virtual que teve intenso processo de penetração nos últimos dez anos, desdobrando-se, por exemplo, na criação de avatares ${ }^{36}$ (corpos inteiramente virtuais). A discussão dos ciborgues se depara com o cenário do pós-humano no qual o ideário virtual vê na materialidade do corpo uma viscosidade incômoda, um entrave à liberação imaterial, [onde] somos todos handicapés ${ }^{37}$. A metáfora dos ciborgues se depara com situações de diagnóstico nas quais os antigos organismos entram em cena, pois se os organismos não entram nos laboratórios de biotecnologia ou nas simulações virtuais, de algum modo o fazem num consultório médico quando esbarram no limite da dor física que ainda não aprendemos a transferir para o corpo imagético ${ }^{38}$.

\footnotetext{
${ }^{33}$ Le Breton, op.cit.

34 "Cyborg 009 é outra obra prima, desta vez do gênio Ishinomori Shotaro. Nove humanos foram transformados em super ciborgues contra vontade pela maquiavélica Organização do Fantasma Negro. Agora esses nove ciborgues se uniram para combater juntos a Organização. O herói da história é o ultimo ciborgue, 009 (leia em inglês, zero-zero-nine, ou seja, zero-zero-nove), que é metade americano e metade japonês e equipado com os mais poderosos equipamentos de super velocidade e habilidades excepcionais. Cyborg 009 é sucesso nos Estados Unidos entre as crianças e adolescentes de todas as idades, com 51 episódios. No Brasil, os primeiros 26 episódios já estão dublados" www.ig.com.br/ultimosegundo.

${ }^{35} \mathrm{http}: / /$ www.trugjumpou.com.br/sistemas/outros/cyberpunk2020.asp

${ }^{36}$ Ver trabalho de Victoria Vesna.

${ }^{37}$ Pelbart, P. (2003) O Corpo do Informe. In: Leituras do Corpo. São Paulo: ed. AnnaBlume.

${ }^{38}$ Lê Breton. Adeus aos corpos. In: Homem-máquina.
} 
Uma certa inquietação com relação às conexões que poderiam ser estabelecidas com a figura do ciborgue aparece no prefácio a edição espanhola feito por Jackie $\operatorname{Orr}^{39}$ que já apontava que o compromisso de Haraway com a ciência e seus artefatos tecnológicos perigosamente poderosos a arrasta ao desejo prático, porém difícil, de reconstruir os mundos 'reais' mediante o conhecimento e as práticas tornadas possíveis pela ciência moderna ${ }^{40}$. E, perguntava: que aspecto tem um ciborgue fora do umbigo do monstro que o (re)produz ? $^{41}$, apontando que para algumas pessoas, os ciborgues podem resultar mais em uma imagem ambivalente de um "outro" do que uma reconfiguração provocativa de um "eu". Que ciborgues povoam os nossos e outros sonhos?

O horizonte da reflexão que proponho não coincide com a conservação do corpo como uma entidade em si, natural, a ser conservada. A reflexão se volta para pensar nas conexões superficiais, associações e atividades derivadas das misturas dos ciborgues ao imaginário tecno-científico contemporâneo. Trata-se de perguntar se insistir no ruído e nas fusões constitui ainda uma ferramenta de oposição ou se a cultura de alta tecnologia ainda desafia os dualismos de maneira curiosa; perguntar se a figura do ciborgue conforme ingressaram na vida cotidiana ainda define possibilidades e limites bastante diferentes dos propostos nas ficções mundanas entre homens e mulheres ${ }^{42}$.

O ciborgue ainda constitui uma figura monstruosa? A figura dos ciborgues consegue fugir do avizinhamento com o universo neo-gnóstico atual? Está na passagem do monstruoso ao registro do normal/anormal? Cerca de quinze anos depois da publicação do texto de Haraway, pode-se de dizer que nos ciborgues existe um sistema de mitos a espera de ser uma linguagem política que sirva de semente para uma forma de olhar a ciência e tecnologia e que ameace à informática da dominação, ${ }^{43}$ para atuar poderosamente ${ }^{44}$ ?

Deslocando a discussão para o campo da sociabilidade com objetos, Francisco Tirado escreve que na figura do ciborgue "o objeto não é definido como alteridade do sujeito humano, nem é conceituado como mesmidade, mas é transformado em informação permanentemente circulante". Francisco Tirado pontua que os ciborgues nos remetem nos impelem a um pensamento do fluido ${ }^{45}$ e a um pensamento que seja fluido ${ }^{46}$. Desenvolve uma crítica mordaz à busca por um corpo de carne

${ }^{39}$ Orr, J. (1995) ?Feminismo de Ciencia ficción? Prefacio à edição espanhola Ciência, cyborgs y mujeres.

${ }^{40}$ Orr, J, op. cit., pp. 48.

${ }^{41}$ Orr, J, op. cit., pp. 51.

${ }^{42}$ Haraway, op. cit., pp. 309.

${ }^{43}$ A utilização estratégica das novas formas de tecnologia como resistência tem sido proposto pelo movimento ciberpunk desde os anos oitenta. www.facom.ufba.br/ciber.htm.

${ }^{44}$ Haraway, pp. 310.

${ }^{45}$ A fim de fazer frente a esse novo tecido social, alguns pesquisadores têm se empenhado, por exemplo, John Law e Anne Marie Mol que em 1994, num estudo sobre anemia, propõe que a ontologia da anemia é heterogênea e só pode ser decidida empiricamente. $E$, desenvolvem a noção de espaços sociais que atuam como fluidos e são transformados sem fraturas, o que não coincide com redes estáveis. Parte-se do princípio de que não há definição ontológica prévia, nem dos objetos, nem das pessoas; longe do sólido, próximo do fluido; longe da materialidade sólida e perto das multiplicidades descontínuas.

${ }^{46}$ Ouve-se também a voz de Michel Serres a fim de compor interpretações menos atreladas ao sólido, mas próximas aos fluxos que escreve: "Era uma vez a idade de ouro. Onde e quando, ignoro. Depois dela, vieram a idade de bronze e o século do ferro. Mitos ou histórias, sempre metais. Metais ou então pedra: polida, lascada, neolítica ou paleolítica. Não sabemos falar senão de sólidos, não sabemos senão escrever sobre sólidos. (...) Eis as águas, cataratas e fluxos [...]O turbilhão forma-se 
originário, propondo uma análise do corpo como conjunto de fluxos, reafirmando a necessidade de abandonar a carnalidade do corpo e se voltar para o regime de corporeidade e de conexão, dando como exemplo o caso de mulheres que usam pulseiras de detecção e o do controle aberto e contínuo que passa a governar no lugar do confinamento. A proposição é de dissolução do corpo de carne enquanto categoria analítica se aproxima da ênfase nas conexões característica da tecnociência, mas distancia-se das propostas neognósticas que discutimos antes quanto à exaltação do espírito/informação/máquina.

A reflexão sobre os ciborgues faz eco à reflexão sobre o princípio de simetria generalizada ${ }^{47}$ no qual todos os entes sejam eles humanos ou não, possuem potencialmente o mesmo poder de ação; deve ser usada uma mesma explicação. Lucy Suchman $^{48}$ argumenta que não se trataria de analisar simetricamente todos os entes envolvidos na produção de tecido social, pois haveria entre eles diferenças de constituição histórica que não devem ser obscurecidas ao custo de uma simetria ou mesmo poder de ação atribuído a qualquer dos entes. Propõe o uso da noção de "constituição mútua". Falar em constituição mútua não implica necessariamente em atribuir um mesmo poder de ação a qualquer dos entes.

Suchman aponta "que as fronteiras entre humanos e máquinas não são naturais, mas construídas, por meio de caminhos históricos particulares e com conseqüências históricas particulares ${ }^{49 "}$. Nesse sentido, os entes que compõe um ciborgue teriam uma história, de modo que deveria ser considerada uma certa ontologia prévia ao momento de interação; do agenciamento em análise.

Concordo parcialmente com Suchman e talvez tenhamos que criar historicidades contextuais à coreografia ontológica que se faz entre máquinas e pessoas, pois estas se alteram ao longo de um processo de interação. Para ilustrar basta pensar em um processo de acompanhamento contínuo de um usuário soropositivo (os diversos devires que ora podem avinha-lo à máquina; informação ou à carne) e as relações/fluxos de controle que uma metáfora de fusão ou de simetria que não considere a historicidade anterior ao momento talvez pudesse obscurecer ${ }^{50}$. Não tenho resposta, tenho apenas um conjunto de questões.

Como manter a tensão que marca as relações de poder num contexto marcado por fluxos? Trata-se de conferir a humanos e não humanos o mesmo poder de ação? Trata-se de propor um mesmo princípio de explicação simétrico? Ou trata-se de conservar uma certa assimetria entre humanos e não humanos, o que de algum modo refaz parte de uma dicotomia que a duras penas temos procurado superar?

Sem dúvida constituir desafio evitar tomar parte nessa nova docilização do corpo que o compõe como atravessado por fluxos; corpo imaterial; de densidade variável; corpo de anjos; corpo devassado e controlado por dispositivos portáteis, mínimos, invisíveis ou incapazes de serem resgatados uma vez transpassada a pele. É isso não se trata de demonizar a tecnologia, nem propor um corpo carnal

e desfaz-se, na incerteza, mas em qualquer outra parte e planície está tranqüila, assim e assim. Espaço semeado de circunstâncias. Inventar a história líquida e as idades das águas (Serres)."

${ }^{47}$ Termo originalmente usado por Michel Callon

${ }^{48}$ Lucy Suchman. Human/machine reconsidered. Kork-in-progress para segunda edição do livro Plans and situated actions: the problem of human-machine communication publicado originalmente em 1987.

${ }^{49}$ Suchman, L. (s/d); p. 15.

50 Refaz-se aqui uma velha discussão entre analistas de conversão e estudiosos de práticas discursivas numa orientação focauniana quanto ao papel da história e o seu modo de utilização. 
originário, mas de refletir sobre um dispositivo analítico num contexto marcado pela simultaneidade de relações de poder abertas/contínuas, a exemplo do controle virtual feito por máquinas de medição que acompanham os pacientes em suas casas e relações fechadas/discretas cujo exemplo pode ser encontrado em internações médicas em ambientes hospitalares.

E, aqui vale retomar um dos princípios de desnaturalização que orientou a formulação da metáfora do ciborgue, o de que o estabelecimento das fronteiras ou dos traçados corporais é uma questão conceitual e política e que o melhor modo de ver mais amplamente é ver a partir de algum lugar. Talvez o problema esteja em tomar a figura do ciborgue como categoria de classificação e não como uma metáfora que em determinado momento funcionou como uma figura de borda, capaz de fazer ruir um conjunto de dicotomias.

\section{Referencia}

Galindo, D. C. (2003). Sobre os ciborgues como figuras de borda. Athenea Digital, 4. Referencia. Disponible en http://antalya.uab.es/athenea/num4/galindo.pdf 